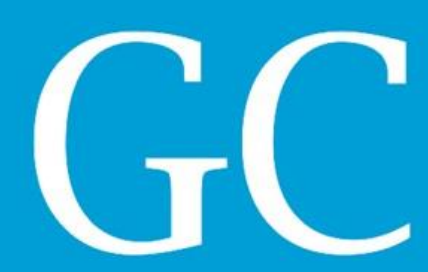

ISSN 2318-8472

v. $06, \mathrm{n} .43,2018$

Revista Nacional de

Gerenciamento de Cidades

National Journal of Cities Management

\title{
Intervenções para a velhice: a (dis)função social da cidade.
}

Interventions for old age: the social (dys)function of the city.

Intervenciones para la vejez: la (dis)función social de la ciudad.

Filipe Augusto Portes

Mestrando pelo Programa de Pós Graduação em Gerontologia, UFSCar, Brasil.

fi.augusto.portes@gmail.com

\section{Luciana Márcia Gonçalves}

Doutora em Arquitetura e Urbanismo e docente do Programa de Pós Graduação em Engenharia Urbana, UFSCar, Brasil. arq.luciana.ufscar@gmail.com

\section{Luzia Cristina Antoniossi Monteiro}

Doutora em Engenharia Urbana e docente do Programa de Pós-Graduação em Gerontologia, UFSCar, Brasil.

cristinaantoniossi4@gmail.com 


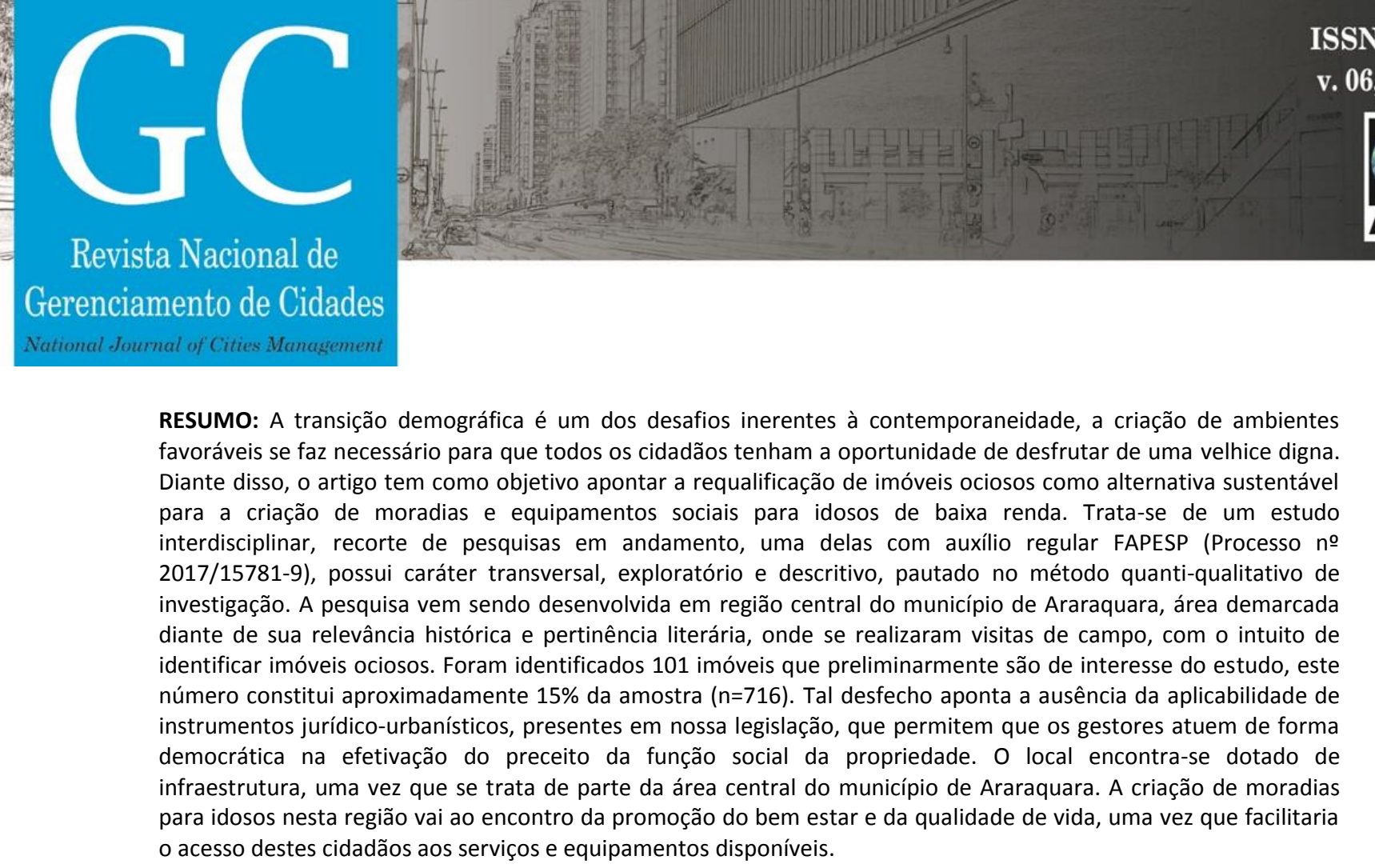

PALAVRAS-CHAVE: Envelhecimento. Planejamento Urbano. Função Social da Cidade.

ABSTARCT: The demographic transition is one of the challenges inherent in contemporaneity, the creation of favorable environments is necessary so that all citizens have the opportunity to enjoy a dignified old age. Therefore, the article aims to point out the requalification of idle real estate as a sustainable alternative for the creation of housing and social facilities for low income elderly people. It is an interdisciplinary study, a research cut in progress, one of them with regular FAPESP assistance (Process no 2017 / 15781-9), has a transverse, exploratory and descriptive character, based on the quantitative-qualitative method of investigation. The research has been carried out in a central region of the municipality of Araraquara, an area demarcated in view of its historical relevance and literary relevance, where field visits were carried out in order to identify idle properties. A total of 101 properties were identified, which are preliminary to the study; this number constitutes approximately $15 \%$ of the sample $(n=$ 716). This conclusion points to the absence of the applicability of legal-urbanistic instruments, present in our legislation, that allow managers to act in a democratic way in the implementation of the precept of the social function of property. The place is endowed with infrastructure, since it is part of the central area of the municipality of Araraquara. The creation of homes for the elderly in this region is in line with the promotion of well-being and quality of life, since it would facilitate the access of these citizens to the services and equipment available.

KEY WORDS: Aging. Urban planning. Social function of the city.

RESUMO (ES): La transición demográfica es uno de los desafíos inherentes a la contemporaneidad, la creación de ambientes favorables se hace necesario para que todos los ciudadanos tengan la oportunidad de disfrutar de una vejez digna. Por lo tanto, el artículo tiene como objetivo apuntar la recalificación de inmuebles ociosos como alternativa sostenible para la creación de viviendas y equipamientos sociales para ancianos de bajos ingresos. Se trata de un estudio interdisciplinario, recorte de investigaciones en curso, una de ellas con ayuda regular FAPESP (Proceso no 2017 / 15781-9), posee carácter transversal, exploratorio y descriptivo, pautado en el método cuanticualitativo de investigación. La investigación viene siendo desarrollada en región central del municipio de Araraquara, área demarcada ante su relevancia histórica y pertinencia literaria, donde se realizaron visitas de campo, con el propósito de identificar inmuebles ociosos. Se identificaron 101 inmuebles que preliminarmente son de interés del estudio, este número constituye aproximadamente el $15 \%$ de la muestra $(n=716)$. Este resultado apunta la ausencia de la aplicabilidad de instrumentos jurídico-urbanísticos, presentes en nuestra legislación, que permiten que los gestores actúen de forma democrática en la efectividad del precepto de la función social de la propiedad. El local se encuentra dotado de infraestructura, ya que se trata de parte del área central del municipio de Araraquara. La creación de viviendas para ancianos en esta región va al encuentro de la promoción del bienestar y de la calidad de vida, ya que facilitaría el acceso de estos ciudadanos a los servicios y equipos disponibles.

PALABRAS CLAVE: Envejecimiento. Planificación Urbana. Función Social de la Ciudad. 


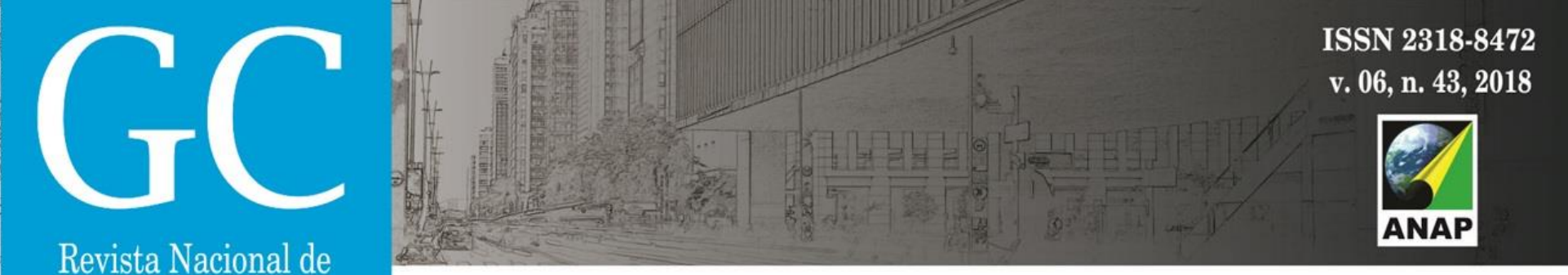

Gerenciamento de Cidades

\section{1 - INTRODUÇÃO}

Dentre os desafios inerentes a contemporaneidade a transição demográfica se destaca como fenômeno que atua de maneira inédita em uma série de países, como no Brasil. Estudos apontam que este fenômeno será contínuo pelas próximas décadas, as projeções reforçam tal afirmativa e mostram que em 2050 um em cada três brasileiros terá idade igual ou superior à 60 anos (IBGE, 2015).

É certo que este cenário traz consigo demandas que agem em todos os setores da sociedade, como é o caso do meio urbano. A estruturação de ambientes acessíveis, que sejam favoráveis à velhice é um dos principais desafios para a oferta do envelhecimento saudável, dotado de qualidade de vida. Sendo assim, as cidades necessitam se adequar à esta realidade (ORGANIZAÇÃO MUNDIAL DA SAÚDE, 2015).

Lefebvre $(2008$, p. 119$)$ afirma que "A estratégia urbana baseada na ciência da cidade tem necessidade de um suporte social e forças políticas para se tornar atuante".

Diante disso, o presente estudo destaca à importância de políticas públicas habitacionais, voltadas para pessoas idosas de baixa renda. Essa demanda se realça frente aos novos arranjos familiares, que resultam na diminuição da participação familiar no cuidado ao idoso, aumentando o número de pessoas acima dos 60 anos morando sozinhas (DEBERT, 2012; IBGE, 2013).

A criação de moradias sociais para idosos, quando implementada em locais dotados de infraestrutura, como é o caso das regiões centrais dos municípios, potencializa o acesso destes cidadãos aos serviços e equipamentos disponíveis, logo, promove o direito à cidade que muitas vezes é tolhido às pessoas, principalmente àquelas que possuem mobilidade reduzida.

Figueiredo et al. (2017), respaldados por Focault (1984), afirmam a existência de uma relação entre o direito à cidade e o direito à saúde. Afinal, na medida em que os espaços urbanos se tornam inclusivos, passam a proporcionar à saúde por meio da distribuição acessível se serviços determinantes na condição de vida da população.

Concomitantemente, a literatura evidencia que os municípios experimentam um fenômeno recorrente, onde passam por esvaziamento característico em suas regiões centrais. Tal ocorrência é fruto de fatores resultantes de séculos de processo de urbanização, onde ocorreu de maneira geral o espraiamento desenfreado das malhas urbanas, que se atrela à especulação imobiliária (VARGAS; CASTILHO, 2015).

Diante disso, o número de imóveis ociosos passa aumentar nestas áreas, permanecendo muitas vezes nesta condição por anos. Essa ocorrência é incompatível com o preceito da função social da propriedade, presente na legislação brasileira. A Lei Orgânica Municipal de Araraquara também reforça essa questão:

Art. 152. A política urbana a ser formulada no âmbito do processo de planejamento municipal terá por objetivo o pleno desenvolvimento das 
funções sociais da cidade e o bem-estar de seus habitantes, obedecidas as normas gerais fixadas em lei federal, mediante a implementação dos seguintes objetivos: (...) $\mathrm{VI}$ - controle do uso do solo de modo a evitar: (...)

b) a ociosidade, subutilização ou não utilização do solo urbano edificável. (ARARAQUARA, 1990).

Vargas e Cartilho (2015) apontam que intervenções urbanas nas regiões centrais das cidades veem ocorrendo em diferentes municípios do Brasil, com o intuito de combater a ociosidade de imóveis e os déficits causados por tais. Essa tendência tem caráter mundial e volta-se para o processo de sustentabilidade das cidades, uma vez que visa utilizar espaços já dotados de infraestruturas, para aproximar cidadãos dos equipamentos e serviços disponíveis, logo do direito à cidade.

Dentre as intervenções aplicadas nos centros dos municípios, a presente pesquisa destaca brevemente à requalificação e a reabilitação urbana. As quais se diferem da seguinte maneira:

a reabilitação urbana se dirige mais ao edificado, sobretudo o que tem a ver com a função residencial, a requalificação urbana dirige-se mais ao seu entorno e ao espaço público, ou, nas operações urbanas de larga escala, à reconversão funcional de um dado espaço (PEIXOTO, 2009, p. 46).

Neste sentido, o presente estudo se caracteriza como recorte de um projeto maior em desenvolvimento que visa propor como alternativa à demanda habitacional a reabilitação e requalificação de imóveis ociosos, a fim de que estes venham a compor moradias sociais ou equipamentos para idosos de baixa renda. Sendo assim, analisa a existência de vazios urbanos em uma área da região central do município de Araraquara - SP.

\section{2- OBJETIVO}

Apontar a requalificação de imóveis ociosos como alternativa sustentável para a criação de moradias e equipamentos sociais para idosos de baixa renda, diante do envelhecimento populacional.

\section{3 - METODOLOGIA}

Trata-se de um estudo interdisciplinar, de caráter transversal, exploratório e descritivo, método quanti-qualitativo de investigação. A utilização da abordagem metodológica mista permite a integração de resultados quantitativos e qualitativos de forma confiável, através da descrição e da observação (LORENZINI, 2017).

Minayo (2014), afirma que tal abordagem pode conduzir a resultados importantes a respeito da realidade social a partir de medidas simultâneas em curto período de tempo, em população definida, e sem atribuição de prioridade de um sobre o outro.

Consiste em recorte de um projeto maior, intitulado "Direito à Cidade e Pessoa Idosa: proposta de requalificação de imóveis ociosos", realizado com auxílio regular FAPESP (no 
2017/15781-9). Também consiste um recorte da dissertação de mestrado intitulada "Políticas Públicas e Imóveis Ociosos: aplicabilidade da função social da propriedade na moradia do idoso de baixa renda".

Sendo assim, o presente artigo apresentará resultados preliminares de ambas as pesquisas, as quais encontram-se em processo de desenvolvimento. Portanto, irá destacar a delimitação da área do estudo e os achados obtidos em pesquisa de campo, duas das etapas da coleta de dados.

Além das etapas destacadas, a pesquisa ampliada ainda analisa o acesso ao Cadastro Técnico Municipal de Geoprocessamento - CTMGeo, uma ferramenta multifinalitária de utilização das secretarias de Desenvolvimento Urbano e de Gestão e Finanças vinculadas à Prefeitura Municipal de Araraquara. Tal mecanismo permite a checagem de dados relacionados às propriedades, bem como dispõe a localização geoespacial destes, colaborando para a seleção de imóveis de interesse do estudo.

A coleta de dados também contará com a verificação do consumo de água dos imóveis selecionados em visitas de campo, em parceria com o Departamento de Água e Esgoto de Araraquara - DAAE. As contas que apontarem consumo zero ou próximo de zero, fortalecerão o levantamento realizado nas visitas de campo.

Por fim, será realizada pesquisa na legislação brasileira, que buscará verificar instrumentos jurídico-urbanísticos que viabilizem a reabilitação e a requalificação da propriedade, assim como seus respectivos funcionamentos.

\section{1 - COLETA DE DADOS.}

\subsection{1 - LOCAL DO ESTUDO E DEMARCAÇÃO DO “QUADRILÁTERO HISTÓRICO”}

A cidade de Araraquara apresenta uma população estimada de 230.770 habitantes. De acordo com o último censo, realizado em 2010, conta com uma população total de 208.662 cidadãos, onde destes, 29.115 (14\%) possuíam 60 anos de idade, ou mais. A tendência é que assim como a população total, o número de idosos também tenha crescido desde então (IBGE, 2017).

O município é considerado de médio porte e se situa a $270 \mathrm{~km}$ da capital paulista. Foi indicado em 2015 como a sétima melhor cidade para se viver no Estado de São Paulo, de acordo com o IDH-M (Índice de Desenvolvimento Humano Municipal) que analisa o acesso à educação, renda e expectativa de vida (SÃO CARLOS E ARARAQUARA, 2015).

A região recortada para a realização do estudo foi delimitada por sua condição histórica, sendo denominada para fins da presente pesquisa como "Quadrilátero Histórico". Sendo assim, possui um papel fundamental na identidade do município e contém parte das edificações mais antigas da cidade. Cita-se como exemplo, o casarão que atualmente abriga o Museu Histórico Pedagógico "Voluntários da Pátria", que originalmente era denominado "Palacete São Bento", construído em 1898. 


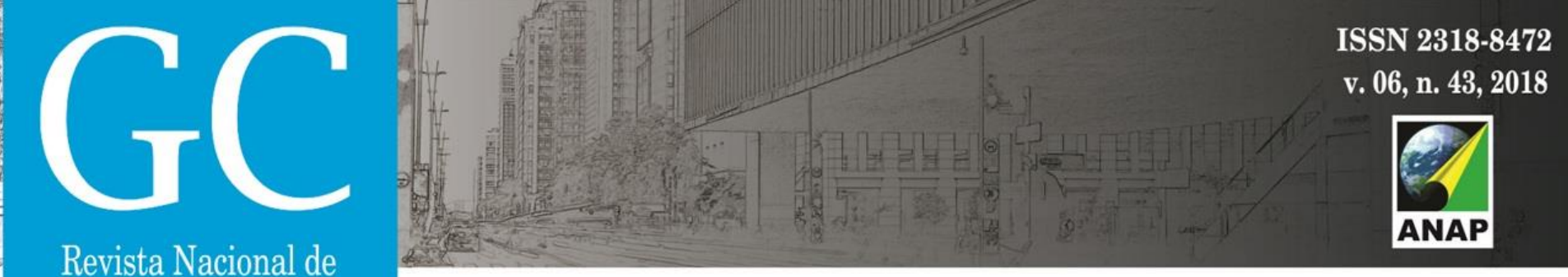

Gerenciamento de Cidades

Tal região consiste em parte da área central de Araraquara, logo, a escolha do local também se embasa diante da literatura científica, que aponta as regiões centrais dos municípios como áreas que sofrem um esvaziamento característico, somado à deterioração imobiliária.

Sendo assim, é limitada por quatro vias que delineiam o quadrilátero em questão e que abrangem 47 quadras. Como marco leste adotou-se a Rua Dr. Antonio Picaron, no sentido oposto tem-se a Rua Humaitá. As avenidas Brasil, e Espanha, demarcam respectivamente os extremos sul e norte. A Figura 1 mostra, em destaque, o recorte realizado para o desenvolvimento da pesquisa, denominado quadrilátero histórico.

FIGURA 1: QUADRILÁTERO HISTÓRICO

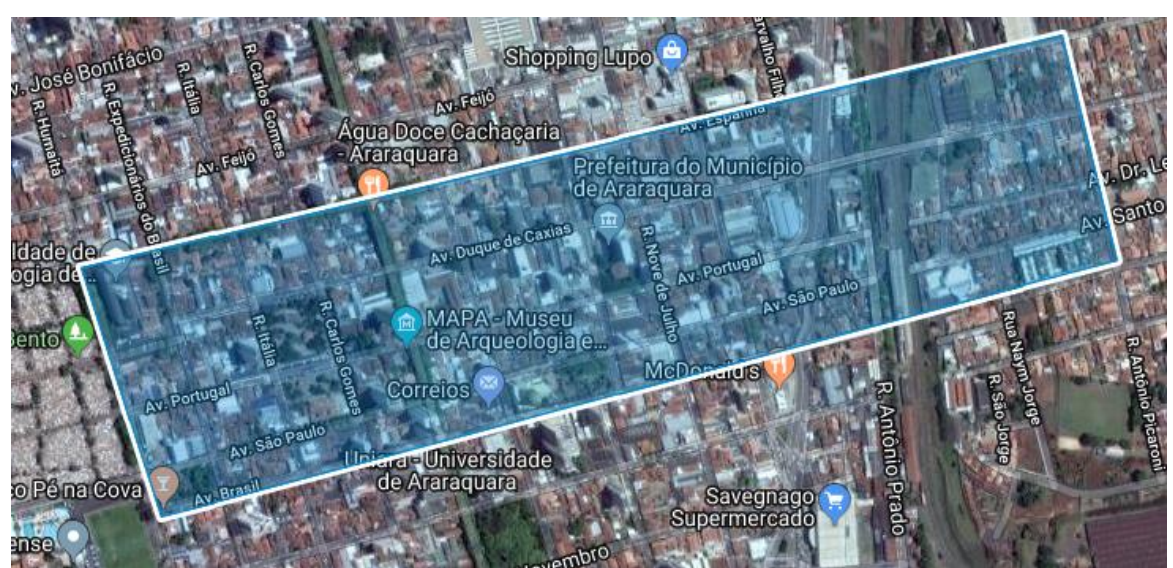

FONTE: GOOGLE MAPS, 2018.

\subsection{2 - REALIZAÇÃO DE VISITAS DE CAMPO}

A realização de visitas de campo ocorreu entre julho e setembro de 2018. Nas ocasiões, os pesquisadores envolvidos percorreram as ruas que compõe o Quadrilátero Histórico, com o objetivo de identificar imóveis que se enquadrassem nas seguintes categorias:

a) Imóvel fechado: considerou-se aquele que aparentemente esteja temporariamente vago, com indicativos de placas como "vende-se" ou "aluga-se";

b) Imóvel em ruína: entendeu-se pelo imóvel com grande deterioração aparente, cujas ações para se intervir demandariam um alto custo financeiro para propiciar possível reutilização (os pesquisadores deverão observar se há presença de telhado, esquadrias e paredes);

c) Imóvel abandonado: considerou-se nessa categoria como sinônimo "ocioso" e "espaço desconstruído livre". Entende-se o imóvel que aparentemente está fechado há algum tempo, em desuso e sem destinação dada pelo proprietário, apresentando condições práticas para intervenção. 


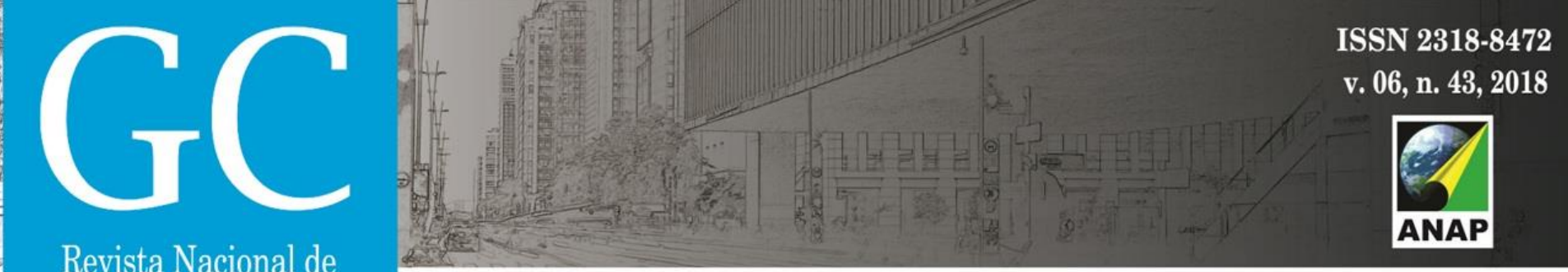

Gerenciamento de Cidades

d) Imóvel inacabado: enquadraram-se os terrenos que possuem edificações inacabadas, somadas às características de abandono, tais como: lote sem carpir, dejetos não comuns à construções etc.

As três primeiras categorias citadas foram preestabelecidas durante a criação do projeto de pesquisa, embasando-se nos achados literários, enquanto a categoria "Imóvel Inacabado" surgiu diante da experiência empírica dos pesquisadores em campo. A classificação destes imóveis levou em consideração elementos visuais e construtivos, os quais foram observados pelos envolvidos durante as visitas.

A presente fase pautou-se no desenvolvimento de um roteiro de campo, que padronizou as coletas e permitiu a associação de cada achado com a categoria que Ihe cabia. Além disso, tal roteiro dispunha de espaço para a realização do croqui da quadra, auxiliando assim, no mapeamento da região em questão. Registros fotográficos também foram utilizados nessa fortalecer os achados no campo.

\section{2- ANÁLISE DOS DADOS.}

Foi realizada a análise estatística simples para as questões e avaliações quantitativas, bem como análise de conteúdo para as questões de caráter qualitativo, de forma sistemática à luz do referencial teórico e normativo sobre o tema da pesquisa (BARDIN, 2016).

\section{4 - RESULTADOS.}

O acesso ao CTMGeo permite afirmar que o Quadrilátero Histórico é composto por 716 imóveis em sua totalidade, sendo que estes têm diferentes finalidades, como residencial, comercial, serviços públicos, etc.

A pesquisa de campo permitiu identificar 101 imóveis que, preliminarmente, são de interesse do estudo e que se relacionam visualmente nas categorias citadas acima. Este número constitui, aproximadamente, $15 \%$ da amostra $(n=716)$. Sendo que 42 enquadram-se na categoria "imóvel fechado", 55 em "imóvel abandonado", três em "imóvel em ruínas" e apenas um em "imóvel inacabado". O gráfico abaixo ilustra a distribuição percentual dos achados: 


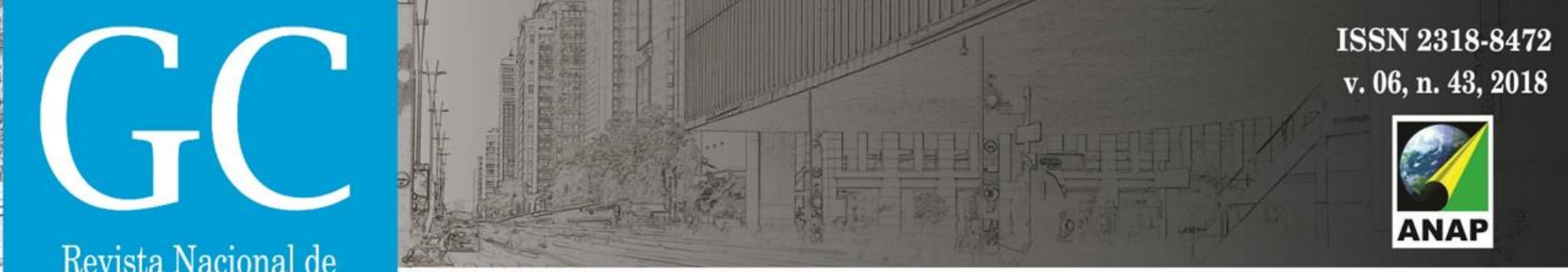

Revista Nacional de Gerenciamento de Cidades

Gráfico 1: Distribuição dos imóveis por categoria

- Fechados Abandonados Em ruínas Inacabados

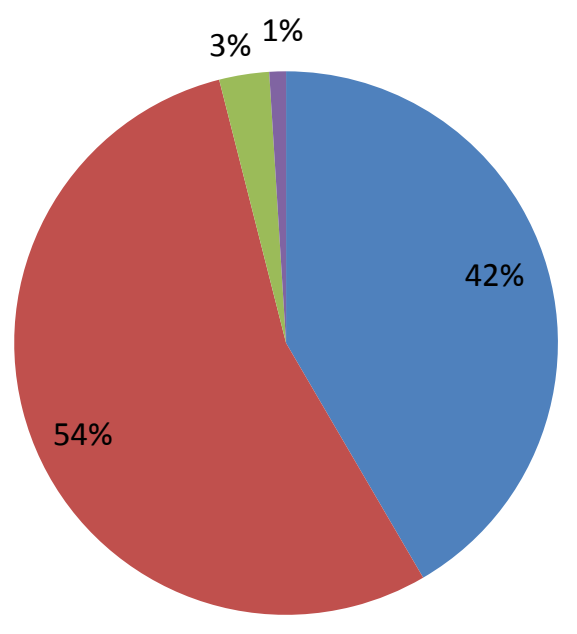

O número de imóveis ociosos identificados no estudo é considerado alto, tendo em vista que representa, aproximadamente, $15 \%$ do número total de imóveis presentes no Quadrilátero Histórico. Por tratar-se de cidade de médio porte, com fortalecido comércio na região central, as hipóteses preconcebidas indicavam quantidade muito inferior aos achados.

Vale pontuar que todas as fases que compõem a coleta de dados são complementares, portanto os resultados finais podem ser alterados a partir da análise integrativa de todas as etapas. Desse modo, a amostra coletada em visita de campo poderá sofrer alterações diante da verificação de outros métodos que ainda comporão a analise final, como o consumo de água. Sobre os imóveis selecionados ao final do estudo poderão recair instrumentos jurídicos cuja finalidade é dar à tais um uso adequado, potencializando políticas públicas habitacionais para idosos.

Cita-se, portanto, o Instituto do Abandono (art. 1.276 do Código Civil), como instrumento possível de aplicação. Tal mecanismo, além de estar presente no Código Civil, foi regularizado em 2012 no município de Araraquara, tornando-se desta maneira a Lei Municipal, no 7.733/12

\section{5 - CONCLUSÃO.}

O envelhecimento populacional é uma realidade que se acentua com o passar dos anos e que deve ser encarado de forma prática. Sendo assim, a implementação de políticas públicas voltadas à população idosa - principalmente àqueles de baixa renda - se faz necessária em todos os setores. Neste sentido, o presente artigo destaca a relevância da utilização de imóveis ociosos, que requalificados podem minimizar a problemática habitacional_e social. 
O local onde o estudo se desenvolve encontra-se dotado de infraestrutura, uma vez que se trata de parte da área central do município de Araraquara. A criação de moradias para idosos nesta região vai ao encontro da promoção do bem estar e da melhora na qualidade de vida, uma vez que facilita o acesso destes aos serviços e equipamentos disponíveis, de forma acessível, por meio da mobilidade oferecida na região.

Os resultados obtidos nas visitas de campo apontam a existência de quantidade expressiva de imóveis que preliminarmente podem ser considerados ociosos, referindo-se à aproximadamente $15 \%$ da amostra. Esse desfecho aponta a ausência da aplicabilidade de instrumentos jurídico-urbanísticos, presentes em nossa legislação, que permitem que os gestores atuem de forma democrática na efetivação do preceito da função social da propriedade e da cidade.

Sabe-se que o município de Araraquara não dispõe de mapeamento de imóveis ociosos tal como o presente estudo vem realizando. Sendo assim, a pesquisa vislumbra possibilitar que o poder público concretize programas, projetos e ações contemplando a promoção do direito à cidade àqueles que necessitam de amparo institucional, como é o caso da população idosa de baixa renda.

\section{6 - REFERÊNCIAS.}

ARARAQUARA (Município). Prefeitura Municipal. Lei Orgânica do Município de Araraquara. 1990. Disponível em: http://www.camara-arq.sp.gov.br/ImageBank/FCKEditor/file/Legislacao/LOM\%20-\%20\%20Emenda\%2040.pdf Acesso em: outubro de 2018

ARARAQUARA (Município). Prefeitura Municipal. Lei de no 7733, de 24 de maio de 2012. Araraquara. 2012.

BARDIN, L. Análise de conteúdo. São Paulo, Edições 70, 2016.

DEBERT, G. G. A reinvenção da velhice .São Paulo: Editora da Universidade de São Paulo, Fapesp. 2012.

FIGUEIREDO, Glória Lúcia Alves et al. Direito à cidade, direito à saúde: quais interconexões?. Ciência \& Saúde Coletiva, [s.I.], v. 22, n. 12, p.3821-3830, dez. 2017.

FOUCAULT, M. Microfísica do Poder. Rio de Janeiro: Edições Graal, 4ed. 1984.

INSTITUTO BRASILEIRO DE GEOGRAFIA E ESTATíSTICA. (IBGE). Pesquisa Nacional por amostra de domicílio. Rio de Janeiro. 2013.

INSTITUTO BRASILEIRO DE GEOGRAFIA E ESTATÍSTICA. (IBGE). Estudos e Análises. Informação demográfica e socioeconômica. Rio de Janeiro. 2015.

INSTITUTO BRASILEIRO DE GEOGRAFIA E ESTATÍSTICA. (IBGE). Censo Demográfico 2010 - Amostra - Características da população. 2017. Disponível em:

https://cidades.ibge.gov.br/brasil/sp/araraquara/pesquisa/23/25888?detalhes=true Acesso em: setembro de 2018.

LEFEBVRE; H. O direito à cidade. 5. Ed. Centauro Editora, São Paulo, 2008. 


\section{Revista Nacional de}

Lorenzini E. Pesquisa de métodos mistos nas ciências da saúde. Rev Cuidarte. 8(2): 1549-60. Lagos Del Cacique. 2017.

MINAYO, M. C. de S. O desafio do conhecimento: pesquisa qualitativa em Saúde. 11ạ ed., São Paulo/Rio de Janeiro: HUCITEC-ABRASCO, 2014.

ORGANIZAÇÃO MUNDIAL DA SAÚDE. Relatório Mundial de Envelhecimento e Saúde (Resumo). 2015. Disponível em: <https://sbgg.org.br/wp-content/uploads/2015/10/OMS-ENVELHECIMENTO-2015-port.pdf> Acesso em: setembro de 2018.

PEIXOTO, P. Requalificação Urbana. In: FORTUNA, C; LEITE, R. P. Plural de cidade: novos léxicos urbanos. Coimbra: Edições Almedina, p. 41-52. 2009.

SÃO CARLOS E ARARAQUARA. IDH aponta Araraquara como a sétima melhor cidade para se viver em SP.2015. Disponível em: <http://g1.globo.com/sp/sao-carlos-regiao/noticia/2015/06/idh-aponta-araraquara-como-setimamelhor-cidade-para-se-viver-em-sp.html>. Acesso em: setembro de 2018.

VARGAS, H. C; CASTINHO, A. L. H. Intervenções em Centros Urbanos: objetivos, estratégias e resultados. 3. Ed. São Pauo: Manole. 2015. 